\title{
Social Interaction Anxiety and Its Influence on Learning Engagement of Students During COVID-19
}

\author{
Abhishek J M Nair ${ }^{1}$, Sreejith Sreekumar ${ }^{2 *}$
}

\section{ABSTRACT}

Individuals with social interaction anxiety often tend to hold specious beliefs about the level to which others experience symptoms of social anxiety and how others evaluate people who appear to be anxious. The purpose of this study was to: (a) to gauge the level of social interaction anxiety among students to find out how it will affect them in the long run with the adoption of the virtual platform (b) to examine the relationship between social interaction anxiety and learning engagement. The study has thus looked into the relationship between the factors like social interaction anxiety, COVID fear and student engagement. A theoretical model was developed using selected variables and the model was then tested with the help of a structured questionnaire which was circulated among 300 respondents of which 250 responses were received. Analysis of the model using WarpPLS-SEM pointed to few important constructs that resulted in social interaction anxiety. Results depicted that a vast majority of individuals experience symptoms of social interaction anxiety from time to time. We have analyzed the social interaction anxiety on student engagement and from the result, we have found out that due to COVID fear, the social interaction anxiety has increased resulting in the decrease of student learning engagement.

Keywords: Social Interaction Anxiety (SIA), Student engagement, COVID-19, Fear

$\mathrm{S}$ ocial Interaction Anxiety is a common mental health issue faced by students. It is defined as the distress faced by individuals while interacting with people, whether they be friends, members of the opposite sex, or strangers. These people living with social anxiety try to evade regular interactions with others. Bernstein et al. (2007) found that the severity of SIA was correlated with shortages in social skills, difficulties in learning and attention.

\section{Social interaction anxiety and learning engagement}

The affected by social interaction anxiety will miss self-development opportunities as they will try to avoid interactions, physically or mentally. Attention to academics may be distracted by an excessive focus on their anxieties (Clark \& Wells, 1995). In a learning scenario, the social performance of the students are highly entrusted upon social interactions,

\footnotetext{
${ }^{1}$ Department of Management, Amrita Viswa Vidyapeetham, Kochi, India

${ }^{2}$ Department of Management, Amrita Viswa Vidyapeetham, Kochi, India *Corresponding Author
} 
since the students are expected to speak before a large group during lectures, seminars, presentations, group discussions and interviews. Social interaction anxiety may pose a lot of inhibitions towards students while participating in learning situations, as it may weaken the quality of student life thereby negatively affecting the future performance of the students.

\section{Impact of COVID-19 on social interaction anxiety}

Due to the COVID-19 pandemic, many countries responded with lockdowns and other restrictions. As a result, all the social interactions have become virtual, so the chance of meeting people in person and socializing has significantly been reduced. The schools and universities suspended classroom teaching and switched to the online mode of teaching making about 1.5 billion students globally remain at home. Because of this, students are motivated to be more active virtually and the social interactions among peers are dropping day by day. The exposure to these unprecedented times has caused a lack of social interactions among peers, inducing negative feelings of anxiety. So in the long run, if they want to be active in a physical environment, they may face social interaction anxiety and it may affect their learning engagement.

The primary aim of this study is to gauge the level of social interaction anxiety among students and to find out how it will affect them in the long run due to the adoption of the virtual platform.

The secondary objective is to examine the relations between social interaction anxiety and student engagement.

\section{REVIEW OF LITERATURE}

\section{COVID 19 and social interaction anxiety}

Severe acute respiratory syndrome coronavirus-2 (SARS-CoV-2), referred to as COVID 19, was initially diagnosed in Wuhan, China in December 2019. In India, the first case was reported from Kerala on January 13 2020, currently, the coronavirus has affected 219 countries around the world. The WHO instantly declared the crisis as a global pandemic on March 11. As of $23^{\text {rd }}$, January 2020, 96.2 million total cases were reported globally and 21,16438 casualties were reported till now. People have been advised to follow a few stringent preventive measures such as maintaining social distancing, compulsory usage of mask, and sanitisers. During the pandemic, people are prone to phobias such as fear of getting diseased because of person-to-person transmission of the virus. A recent study "Assessment of the psychometric properties of the fear of COVID-19 Scale" disclosed that the item 'I am afraid of losing my life because of COVID-19' is the most contributing factor, that one's worry about one's own fatality risk is highly predictive of broad fears of the virus. The fear of coronavirus disease may bring out anxiety, stress, and depression which may eventually lead to (Hall et al. 2008) disorders like agoraphobia (an anxiety disorder characterized by a fear of being outside the home.)

\section{Social Interaction Anxiety}

SIA can be defined as "marked fear or anxiety about one or more social situations during which the individual is exposed to possible scrutiny by others." SIA is one of the most common mental health problems that arise due to agony and infirmity.

Social Anxiety Disorder affects both mind and body alike, which can eventually lead to emotional, physical and behavioural symptoms. People with this disorder may fear appearing anxious, with signs like blushing or trembling, or others finding them stubborn. 
People with Social anxiety disorder also show some physical symptoms like sweating or increased heart rate. During COVID-19 pandemic, health officials have issued guidelines to maintain social distancing. Social distancing may provide people with social anxiety a temporary relief, however, a lack of interaction may make matters worse. When social distancing is no longer required, people with a social interaction anxiety disorder may struggle to carry out their normal activities after being isolated for a long time. (Jessica Caporuscio, Janet Brito)

Anxiety disorder is influenced by genetic as well as environmental factors (Gross, C., \& Hen, R.). In this context, COVID 19 is an environmental factor so it can affect social interaction anxiety

\section{Student engagement}

Student engagement can be defined as the degree of attention, curiosity, interest, optimism, and keenness that students show once they are learning or being taught, which extends to the extent of motivation they need to find out and progress in their education. it's shaped by a variety of complex interplay of relationships, learning activities, and therefore the learning environment.

Student engagement is linked with better accomplishment, perseverance and retention with disentanglement having a reflective effect on mental development and student learning engagement.

During the pandemic students were forced to take up online classes, this took a toll on their social interaction and relationship with students as well as teachers. Students attend online classes at the comfort of their homes at a later point of time when the situation is normal students may find it difficult to cope with the normal physical classroom environment.

In this review of literature, we have discussed Covid fear, social interaction anxiety and student engagement. To our knowledge, the prevalence of Social interaction anxiety and its influence on the learning engagement of students during COVID-19 is largely understudied. The pandemic has brought a drastic change in the social interactions which may lead to anxiety disorders, which in turn affect student engagement.

Our aim of the study is to identify the relationship between COVID Fear, Social Interaction Anxiety and Student Engagement.

\section{METHODOLOGY}

\section{Questionnaire development}

The data collection was done using a structured questionnaire. We have used an established scale from previous studies to measure all the variables. All the constructs used in this study are frequently used in various literature related to social psychology. All the items were analyzed using a five-point scale, in which strongly disagree is represented as 1 and strongly disagree as 5 .

\section{Data and Sample}

The study was conducted on social interaction anxiety and its impact on student learning engagement during the pandemic. With the application of a convenience sampling method, a structured questionnaire was prepared and distributed on various online platforms to verify the hypothesis. The data were analyzed with the help of WarpPLS 7.0. SEM (Structural 
equation modelling) analysis was conducted. The survey was completed by 230 participants. Following are demographic characteristics of the respondents: We received responses from 98 males $(42.6 \%)$ and 131 females $(57 \%)$ whereas the remaining 1 respondent preferred not to disclose the gender. We have collected the responses from respondents above 15 years of age.

\section{Social Interaction Anxiety Scale}

Here we have used a 9 item scale to access the social interaction anxiety of the students. Among those 9 items, 5 of them were modified. For eg, a statement "I become tense if I have to talk about myself or my feelings." Was modified to "I find it difficult and become tense in expressing my feelings due to the restriction caused by the pandemic". The construct of COVID Fear where adopted from the covid scale.

\section{Hypothesis Statement}

Based on the literature the study proposes that:

H1: Here COVID fear has a positive influence on social interaction anxiety during the Covid 19.

$\mathrm{H} 2$ : Social interaction anxiety has a positive influence on student engagement during Covid 19.

H3: COVID Fear has a positive influence on student engagement during Covid 19.

\section{Analysis}

Warp PLS 7.0 was used to analyse the proposed conceptual model and to understand the significance of each mentioned variables. The structural equation modelling (SEM) approach was done through Warp PLS for multivariate analysis.

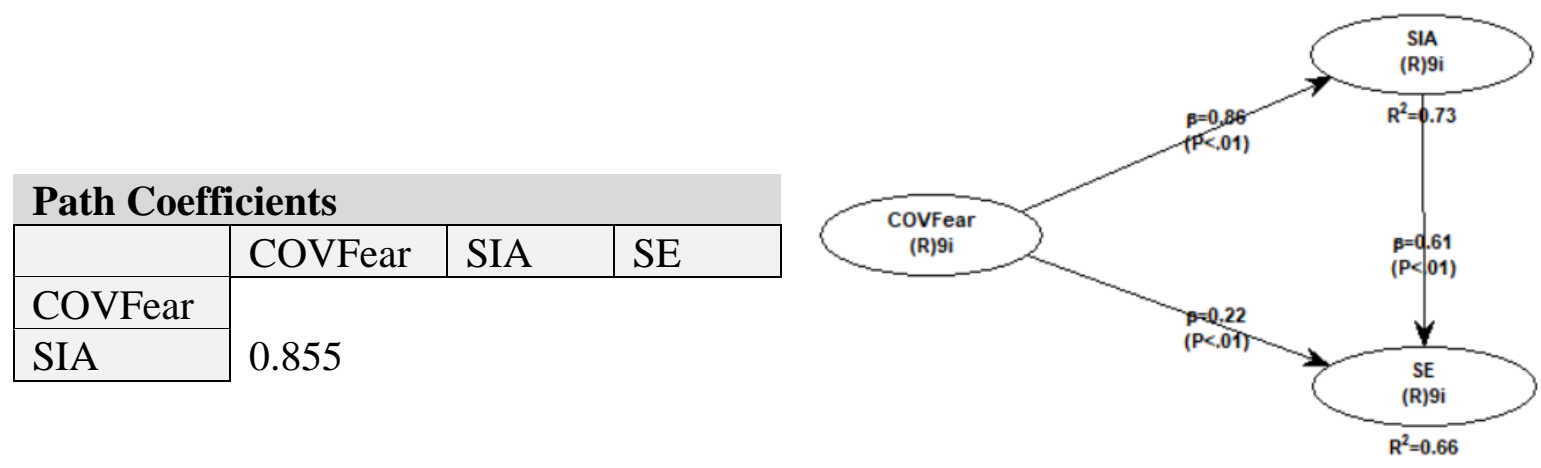

The above theoretical framework depicts the model fit between the independent variables Social Interaction Anxiety (SIA), Student Engagement (SE) and the dependent variable COVFear. All the scales used for measurement is reliable and valid and thus the model is fit, The variable SIA was significant which means that a one-unit change in COVFear leads to a 73\% change in SIA. Student Engagement was also significant; a one-unit change in COVFear leads to a $66 \%$ change in Student Engagement.

\section{(Path coefficient and P-values)}


Social Interaction Anxiety and Its Influence on Learning Engagement of Students During COVID-19

\begin{tabular}{|l|l|l|l|}
\hline P Values & & & \\
\hline & COVFear & SIA & SE \\
\hline COVFear & & & \\
\hline SIA & $<0.001$ & & \\
\hline SE & $<0.001$ & $<0.001$ & \\
\hline
\end{tabular}

The above table shows the $\mathrm{P}$ values and Path coefficients together. In the table, the variables "COVFear" (COVID Fear) and SIA show a value of 0.855 This signifies that the path coefficient directed from "COVFear" to "SIA" is 0.855 , in linear analysis, a path coefficient of 0.855 implies that a one-unit change in the standard deviation of "COVFear" results to 0.855 standard deviation change in "SIA".

In the table, the variables "COVFear" (COVID Fear) and SE show a value of 0.255 This signifies that the path coefficient directed from "COVFear" to "SE" is 0.255 , in linear analysis, a path coefficient of 0.255 implies that a one-unit change in the standard deviation of "COVFear" results to 0.255 standard deviation change in "SE".

The variables "SIA" and SE show a value of 0.607. This signifies that the path coefficient directed from "SIA" to "SE" is 0.607 , in linear analysis, a path coefficient of 0.607 implies that a one-unit change in the standard deviation of "SIA" results in 0.607 standard deviation change in "SE". The cells show P Values $<0.001$ for the independent variables SIA and SE, this means that both the independent variables are significant.

To find the reliability and validity of the construct the Cronbach's $\alpha$ composite reliability and Average Variance Extracted (AVE). Cronbach's $\alpha$ values show the internal reliability of the hypotheses. Here, the $\alpha$ value for each hypothesis ranges between 0.70 and 0.92 , which is higher than the recommended cut-off. The validity of the constructs was measured using composite reliability and AVE values. The composite reliability of all the values ranged from 0.763 to 0.936 , while the value of average variance extracted (AVE) except student engagement (0.33) all the other variables Social interaction anxiety, COVID that meet the accepted criterion.

\section{RESULTS}

The questionnaire contained questions related to the variables that we have selected for this study which are Covid Fear, Social Interaction Anxiety and Student engagement. The respondents were students above 15 years of age. Our target respondents were mainly students having online classes. During the data collection period, we got 230 responses.

Table 1 provides descriptive statistics of respondent characteristics

\begin{tabular}{|l|l|l|l|}
\hline Item & Measure & Frequency & \% \\
\hline Age & $15-20$ & 35 & 15.2 \\
\hline & $21-30$ & 180 & 78.3 \\
\hline & 31 and above & 15 & 6.5 \\
\hline Gender & Female & 131 & 57 \\
\hline & Male & 98 & 42.6 \\
\hline & Others & 1 & 0.4 \\
\hline Stream of Education & BEd & 1 & 0.4 \\
\hline & CA & 2 & 0.9 \\
\hline & Diploma & 1 & 0.4 \\
\hline
\end{tabular}


Social Interaction Anxiety and Its Influence on Learning Engagement of Students During COVID-19

\begin{tabular}{|l|l|l|l|}
\hline Item & Measure & Frequency & \% \\
\hline & Graduation & 68 & 29.6 \\
\hline & Higher Secondary & 7 & 3.0 \\
\hline & Job & 1 & 0.4 \\
\hline & PhD & 5 & 2.2 \\
\hline & Post Graduation & 142 & 61.7 \\
\hline & Secondary & 3 & 1.3 \\
\hline Total & & 230 & $100.00 \%$ \\
\hline
\end{tabular}

The survey was completed by 230 participants. The respondents include 131 females, 98 males and 1 from other categories. In the item stream of education 142 of the respondents were Post Graduates, 68 Graduates, 7 higher secondary etc. The model was estimated using WarpPLS 7.0, SEM (Structural equation modelling) analysis.

We have framed a 9-item scale questionnaire for both independent and dependent variables. For the independent variables, social interaction anxiety we got an adjusted $\mathrm{R}$ squared value of 0.73 and student engagement 0.57 . The $P$ values were less than the significant level 0.05 We have also analyzed the effect of SIA on SE, we got the adjusted R squared value as 0.65 and the P-value is less than 0.01 so the social interaction anxiety has some effect on student engagement.

\section{DISCUSSION}

The pandemic brought about a lot of restrictions like wearing a mask, maintaining social distance and using sanitisers and washing hands in regular intervals. Since the coronavirus is highly contagious people had an aversion towards physical interactions. Our study aims to identify the changes brought about with the advent of COVID-19 in the engagement and the daily routines of a student.

From the study, we found out that students have fear of COVID19. Due to the pandemic classes were made completely online, which led to less physical interaction between the students and teachers. Students found it difficult to concentrate on their online classes which led to a decrease in student engagement. Lack of student engagement in online classes may affect their future performance.

The fear generated due to Coronavirus disease has led to social interaction anxiety from our study we found out that SIA affects their learning process. Nowadays presentations, seminars, GD and interviews are happening completely online where there is no face-to-face interaction. This may lead to social interaction anxiety. In future when students have to interact in a physical world, they may find it difficult to perform due to SIA.

Based on the study we came up with few suggestions firstly the duration of the classes could be reduced. Instead of having classes from morning till evening, schools and collage should make the class around 3-4 hrs. per days so the students can utilize these classes affectively and they can improve their engagement in learning, Secondly, major presentations, seminars and interviews could be conducted offline. In schools/college auditorium strictly enforcing Covid protocols. In future, this might reduce the problems related to social interaction anxiety. 
The findings of the study have interpreted keeping the context of its limitations in mind. One of the thew limitations was the study has considered only three constructs for gauging Social interaction anxiety and its influence on learning engagement of students during COVID-19. The study could be enhanced by adding more variables. The sample size can be expanded to go beyond 350 .

Now there is a gradual change in the trend. Reports show that more people have started travelling within as well as outside the state, Trains and flights have started to commute with full potential, theatres have started to operate with 50\% capacity and some universities have allowed attending examinations offline. The availability of vaccines in India has also led to a reduction in covid fear.

\section{REFERENCES}

Alden, L. E., \& Mellings, T. M. B. (2000). Social phobia and the interpretation of positive events. Paper presented at the Annual Meeting of the Association for the Advancement of Behavior Therapy, New Orleans, LA.

Alden, L. E., Mellings, T. M. B., \& Laposa, J. M. (2004). Framing social information and negative predictions in social phobia. Behaviour Research and Therapy, 42, 585600.

Alden, L. E., \& Wallace, S. T. (1995). Social phobia and social appraisal in successful and unsuccessful interactions. Behaviour Research and Therapy, 33, 497-506.

Baron, R. M., \& Kenny, D. A. (1986). The moderator-mediator variable distinction in social psychological research: conceptual, strategic, and statistical considerations. Journal of Personality and Social Psychology, 51, 1173-1182.

Beck, A. T., Steer, A., \& Brown, K. (1996). Beck depression inventory II. San Antonio, TX: Harcourt Brace.

Brown, T. A., Antony, M. M., \& Barlow, D. H. (1992). Psychometric properties of the Penn State worry questionnaire in a clinical anxiety disorders sample. Behaviour Research and Therapy, 30, 33-37.

Brown, T. A., Dinardo, P. A., \& Barlow, D. H. (1994). Anxiety disorders interview schedule for DSM-IV. New York: Graywind.

Rachel E. Menzies, Ross G. Menzies. (2020). "Death anxiety in the time of COVID-19: theoretical explanations and clinical implications", The Cognitive Behaviour Therapist.

Tooba Khalid, Syeda Hina Batool, Ayesha Khalid, Henna Saeed, Syed Waqas Hussain Zaidi. (2019). "Pakistani students' perceptions about their learning experience through video games", Library Hi-Tech.

Brown, E. J., Turovsky, J., Heimberg, R. G., Juster, H. R., Brown, T.A., \& Barlow, D. H. (1997). Validation of the social interaction anxiety scale and the social phobia scale across anxiety disorders. Psychological Assessment, 9, 21-27.

Crozier \& L. E. Alden (Eds.), International handbook of social anxiety: concepts, research and interventions relating to the self and shyness (pp. 405-430). United Kingdom: John Wiley \& Sons.

Lyubomirsky, S., King, L., \& Diener, E. (2005). The benefits of frequent positive affect: does happiness lead to success? Psychological Bulletin, 131, 803-855.

Mansell, W., Clark, D. M., \& Ehlers, A. (2003). Internal versus external attention in social anxiety: an investigation using a novel paradigm. Behaviour Research and Therapy, 41, 555-572. 
Mattick, R. P., \& Clarke, J. C. (1998). Development and validation of measures of social phobia scrutiny fear and social interaction anxiety. Behaviour Research and Therapy, 36, 455-470.

Christine Purdon, Martin Antony, Sandra Monteiro, Richard P Swinson. (2001). "Social anxiety in college students", Journal of Anxiety Disorders,

Lynn E. Alden, Charles T. Taylor, Tanna M.J.B. Mellings, Judith M. Laposa. (2008). "Social anxiety and the interpretation of positive social events", Journal of Anxiety Disorders.

Ransome Epie Bawack, Jean Robert Kala Kamdjoug. (2020). "The role of digital information use on student performance and collaboration in marginal universities", International Journal of Information Management.

Sho Okawa, Honami Arai, Satoko Sasagawa, Shin-ichi Ishikawa et al. (2021). "A CrossCultural Comparison of the Bivalent Fear of Evaluation Model for Social Anxiety", Journal of Behavioral and Cognitive Therapy.

\section{Acknowledgement}

The author(s) appreciates all those who participated in the study and helped to facilitate the research process.

\section{Conflict of Interest}

The author(s) declared no conflict of interest.

How to cite this article: Nair A J M \& Sreekumar S. (2021). Social Interaction Anxiety and Its Influence on Learning Engagement of Students During COVID-19. International Journal of Indian Psychology, 9(2), 1237-1243. DIP:18.01.130.20210902, DOI:10.25215/0902.130 